"This is a post-peer-review, pre-copyedit version of an article published in Parasitology research. The final authenticated version is available online at: http://dx.doi.org/10.1007/s00436-019-06272-3"

This version is subjected to Springer Nature terms for reuse that can be found at: https://www.springer.com/gp/open-access/authors-rights/aam-terms-v1 


\section{Crenosoma vulpis in red foxes (Vulpes vulpes) in Northern Italy}

Benedetto Morandi ${ }^{1 *}$, Sofia Bertaso ${ }^{1}$, Gary Conboy $^{2}$, Andrea Gustinelli ${ }^{1}$, Roberta Galuppi ${ }^{1}$, Giovanni Tosi $^{3}$, Giovanni Poglayen ${ }^{1}$

${ }^{I}$ Department of Veterinary Medical Sciences, Alma Mater Studiorum University of Bologna, via Tolara di Sopra 50, 40064 Ozzano Emilia (BO), Italy.

${ }^{2}$ Department of Pathology and Microbiology, Atlantic Veterinary College, Charlottetown, Prince Edward Island, C1A 4P3, Canada.

${ }^{3}$ Istituto Zooprofilattico Sperimentale della Lombardia e dell'Emilia Romagna "Bruno Ubertini”(IZSLER), sez. Forlì, Via don E. Servadei 3E/3F, 47122 Forlì, Italy. *Corresponding author: benedetto.morandi2@unibo.it

ABSTRACT: Crenosoma vulpis, the fox lungworm, is a nematode parasite of wild and domestic canids belonging to the super-family Metastrongyloidea. A survey of infection was carried out examining 88 red foxes (Vulpes vulpes) obtained during the regular hunting season (2014-2015) from the EmiliaRomagna region of Italy. Carcasses were stored frozen $\left(-21^{\circ} \mathrm{C}\right)$ prior to necropsy. Lungs were examined for the presence of adult worms by dissection of the trachea, bronchi and bronchioles and then the lung tissue was examined for first-stage larvae (L1) by the Baermann method. No adult stages were detected, but L1, identified based on morphology as Crenosoma vulpis were recovered from $28.4 \%$ (25/88) of the fox lungs. No significant differences in infection were found based on sex or geographical distribution. A brief review on C. vulpis report in red foxes in Italy and other European countries was also carried out.

KEY WORDS: Red fox, Vulpes vulpes, Crenosoma vulpis, Emilia-Romagna, Italy. 


\section{Introduction}

Red foxes (Vulpes vulpes L. 1758) are wild canids worldwide in distribution. They are opportunistic predators, whose varied diet includes: lagomorphs, small and medium-sized rodents, domestic and wild birds, reptiles, invertebrates, but also fruit and vegetables especially in summer and autumn and, if available, also garbage containing food scraps, carrion of domestic and wild ungulates, and aquatic animals such as fish and amphibians (Kidawa and Kowalczyk 2011). Prey availability and geographical setting could affect the parasitic fauna of these animals, including the helminths of the respiratory tract; such as Crenosoma vulpis (Dujardin, 1845) (Nematoda, Metastrongyloidea) and others (Segovia et al. 2004). According to the faunistic and zoogeographical maps (Toso et al. 1999), the red fox is widely distributed in Emilia-Romagna region (Italy), with peaks of 1.38 pairs $/ \mathrm{km}^{2}$ in some areas of the ForlìCesena province, but literature about the presence of fox lungworms in this territory, is still lacking. The objective of this study was to provide data about lungworm infection in red foxes in this part of Italy.

The survey area included the provinces of Forlì-Cesena $\left(2,378.4 \mathrm{~km}^{2} 44^{\circ} 13^{\prime} \mathrm{N} ; 12^{\circ} 02^{\prime} \mathrm{E}\right)$, Rimini $\left(864.88 \mathrm{~km}^{2} 44^{\circ} 03^{\prime} \mathrm{N} ; 12^{\circ} 34^{\prime} \mathrm{E}\right)$ and Ravenna $\left(1,859.44 \mathrm{~km}^{2} 44^{\circ} 25^{\prime} \mathrm{N}\right.$; $\left.12^{\circ} 11^{\prime} \mathrm{E}\right)$ for a total area of $5,102.72 \mathrm{~km}^{2}$ which represents about a quarter of the Emilia-Romagna region $\left(22,452.78 \mathrm{~km}^{2}\right.$, see Fig.1). The northern side of these provinces, which is the more populated and industrialized, is characterized by cultivated and flat lands (Pianura Padana) whereas the southern part is rich in hills and mountains, the top altitude is 1,654 m above sea level (a.s.l) reached by Falterona mount, belonging to the ForlìCesena province. These territories have a subcontinental temperate climate with warm to hot summers and cold winters. In this region the swine industry has great economic importance and must demonstrate the total absence of Trichinella spp. even in wildlife, in order to avoid exportation restrictions, so red foxes, either shot during the regular hunting season or found dead, were delivered to

“Istituto Zooprofilattico Sperimentale della Lombardia e dell'Emilia Romagna” (IZSLER) for trichinosis surveillance. From September 2014 to January 2015, 88 carcasses of red foxes, were delivered to the Forlì IZSLER section and stored at $-21^{\circ} \mathrm{C}$ before necropsy. The respective lungs (with 
or without trachea) were re-stored at $-21^{\circ} \mathrm{C}$ and handed to our laboratory. Each respiratory tract was labeled with information regarding the geographic origin and gender when available. Fifty-one red foxes came from Forlì-Cesena province, thirty-five from Rimini province and just two from Ravenna province. Before analysis, the samples were thawed at room temperature and the trachea, when present, was inspected for macroscopic lesions, then bronchi and bronchioles were carefully dissected, washed and observed for the presence of adult lungworms. Lungs were then chopped into small pieces $(5 \mathrm{~mm})$ and examined for the presence of lungworms first-stage larvae (L1) using the Baermann method according to Lacorcia et al. (2009). Larvae recovered by Baermann examination were identified based on size and morphology. The L1 were measured and the tails were examined under an oil immersion lens and photographed. All microscopic images and measurments were taken using a digital software image processing system NIS-Elements D 4.10.01 64-bH. Each element was identified according to the morphological keys as suggested by McGarry and Morgan (2009) and Conboy (2009).

Prevalence with a 95\% Confidence Interval (CI) was estimated. Range, mean length, standard deviation and median of the detected larvae were also computed. Chi-square test was used in order to assess any statistical difference between gender, provinces and geographical features based on the frequency of parasites, using the software EpiInfo 3.5.1, accepting a statistical significance level for p-value less than 0.05 .

Gender was known for 63 of the 88 foxes collected, with 32 males and 31 females. No adult parasites were found but in 25 foxes, first-stage metastrongyloid L1 were recovered, giving a prevalence of $28.4 \%$ (95\%CI: 19-37.8). A majority of the larvae appeared to be dead but many were recovered alive showing vigorous motility. The range of larvae, detected from each positive lung, run from 1 to $>1000$. Overall, 271 larvae were collected and measured, covering a mean of 10.8 larvae per fox. The mean length of the detected larvae (including the nonviable L1) was $274.48 \mu \mathrm{m}$ (SD $44.29 \mu \mathrm{m})$, with a range from 116.8 to $333.8 \mu \mathrm{m}$. There was a cephalic button at the anterior-end, a sub-dorsal mouth opening, the esophagus was about a third to almost half the length of the larvae and the tail ended in a simple point but had a slight deflection. The larvae were all identified as $C$. vulpis. Larvae of other lungworms which could be found by Baermann examination, such as Oslerus osleri, Filaroides hirthi, F. milksi and Angiostrongylus 
vasorum can be discounted based on morphology. Capillaria aerophila, shedding eggs, is not detectable by Baermann technique.

With respect to gender, L1 were detected in $9 / 32$ males (28\%) and 7/31 females (22.6\%), with no significant differences based on chi-square test $\left(\chi^{2}=0.26, \mathrm{p}=0.613\right)$. No statistical difference $\left(\chi^{2}=0.41\right.$, $\mathrm{p}=0.523$ ) was found comparing the prevalence based on the provinces. For this purpose we took into account just two provinces, Forli-Cesena and Rimini, because only two foxes were from Ravenna province. In addition, we looked for any difference with respect to geographical features, comparing animals from either flatland or hill/mountain regions. Once again no statistical differences were detected $\chi^{2}=1.85, \mathrm{p}=0.174($ Tab. 1$)$.

C. vulpis infects wild -mainly foxes- domestic canids and several other carnivores, dwelling in the bronchioles, bronchi and trachea of the definitive hosts, that aquire the infections by ingesting infective third-stage larvae (L3) present in the tissues of the infected gastropod intermediate hosts (Anderson, 2000). In our work no adult helminths were macroscopically recovered in the trachea, bronchi and lower airways. The frequent lack of the trachea may have contributed to determine an underestimation of the adult presence, even if it has been already reported in dogs by Bihr and Conboy (1999). Moreover, no macroscopic lesions were observed in the trachea, when present, and in the lung parenchyma: this could suggest that the red fox and C. vulpis are well adapted to each other. Infections were detected by the recovery and identification of L1 based on morphology. The presence of a slight deflection to the tail but lacking a kink or dorsal spine and the presence of a subdorsally opening mouth are definitive for $C$. vulpis. Although the measurements of the L1 differ from those observed by McGarry and Morgan (2009) the morphology was consistent with that of $C$. vulpis. The small size of the larvae recovered in this study is likely due to shrinkage occurring during the post-mortem damaging. Despite the freezing at $21^{\circ} \mathrm{C}$ for more than two weeks, some L1 were found still alive. This could explain the survival of this parasite in colder climates, such as Prince Edward Island (Conboy et al. 2017) and Newfoundland (Jeffery et al. 2004).

Overall, high prevalence values for C. vulpis in foxes have been detected in several European countries, which range from $4.5 \%$ in the Netherlands to $58 \%$ in Norway (Tab. 2). In Italy, previous surveys 
performed along the years in other regions using different methods, show prevalence of $C$. vulpis in red foxes ranging from $3 \%$ in Tuscany region to $17,3 \%$ in Trentino Alto Adige (Tab. 2). In the present study, the highest prevalence $(28,4 \%)$ was reported, despite a modest number (88) of examined lungs. It is important to consider the possible role played by foxes as reservoir hosts for domestic animals, as suspected by Tolnai et al. (2015) and Hodžić et al. (2016). Bihr and Conboy (1999) suggested a significant difference in the infection proportions in dogs residing in rural and urban areas, assuming an overlapping in the wild/domestic interface. The spread of foxes into urban areas of European and North American countries and the high prevalence of $C$. vulpis infections may increase the exposure risk of this nematode in companion animals (Traversa et al. 2010); indeed, though neglected in the past, $C$. vulpis infections in dogs have been more often detected and/or recognised as a cause of chronic respiratory disease in various countries in the last fifteen years (Barutzki and Schaper 2011; Barutzki 2013; Conboy et al. 2013; Maksimov et al. 2017). In two recent Italian surveys, one dog out of onethousand was positive (Morelli et al. 2018) as well as five dogs out of $1748(0.3 \%)$ found positive by Brianti et al. (2018). Recently, the spontaneous shedding of L3 in the feces of infected slugs and their survival for up to 120 days free in the environment was reported (Conboy et al, 2017). This suggests the possibility that exposure could also occur through ingestion of L3 present in the environment by the consumption or licking of grass and other plant material, increasing the possibility of transmission. Studies on fox lungworms have relevance in order to deeply understand the role of these wild carnivores in the epidemiology of these parasites related to companion animals. In the near future, veterinary clinicians should consider the possibility of lungworm infections not only in those dogs sharing a high degree of environmental overlap with foxes (such as hunting or truffle dogs) but also in dogs living in urban and suburban areas.

\section{Conflict of interest}

Benedetto Morandi, Sofia Bertaso, Gary Conboy, Andrea Gustinelli, Roberta Galuppi, Giovanni Tosi and Giovanni Poglayen, all together, declare that they have no conflict of interest . 


\section{References}

Anderson RC (2000) The superfamily Metastrongyloidea. In: Anderson RC, editor. Nematode parasites of vertebrates: their development and transmission. 2nd Edition CABI Publishing, Wallingford Oxon (UK), p. 129

Barutzki D, Schaper R (2011) Results of parasitological examinations of faecal samples from cats and dogs in Germany between 2003 and 2010. Parasitol Res 109 (Suppl 1): S45-S60

Barutzki D (2013). Nematode infections of the respiratory tract in dogs in Germany. Tierarztl Prax Ausg K Kleintiere Heimtiere. 41: 326-336

Bihr T, Conboy G (1999) Lungworm (Crenosoma vulpis) infection in dogs on Prince Edward Island. Can Vet J 40: 555-559

Brianti E, Arfuso F, Cringoli G, Di Cesare A, Falsone L, Ferroglio E, Frangipane Di Regalbono A, Gaglio G, Galuppi R, Genchi M, Iorio R, Kramer L, Lia RP, Manfredi MT, Morganti G, Perrucci S, Pessarin C, Poglayen G, Otranto D, Rinaldi L, Scala A, Solari Basano F, Varcasia A, Venco L, Veneziano V, Veronesi F, Zanet S, Zanzani SA (2018) Italian nationwide survey on endoparasites of dogs. XXX Congresso Nazionale SoIPa. p 45

Conboy G (2009) Helminth parasites of the canine and feline respiratory tract. Vet Clin Small Anim 39:1109-1126

Conboy G, Bourque A, Miller L, Seewald W, Schenker R (2013) Efficacy of Milbemax (milbemycin oxime + praziquantel) in the treatment of dogs experimentally infected with Crenosoma vulpis. Vet Parasitol 198: 319-324

Conboy G, Guselle N, Schaper R (2017) Spontaneous shedding of Metastrongyloid third-stage larvae by experimentally infected Limax maximus. Parasitol Res 116: S41-S54 
Hodžić A, Alić A, Klebić I, Kadrić M, Brianti E, Duschera GG (2016) Red fox (Vulpes vulpes) as a potential reservoir host of cardiorespiratory parasites in Bosnia and Herzegovina. Vet Parasitol 223: 6370

Jeffery RA, Lankester MW, McGrath MJ, Whitney HG (2004) Angiostrongylus vasorum and Crenosoma vulpis in red foxes (Vulpes vulpes) in Newfoundland, Canada. Can J Zool 82: 66-74

Kidawa D, Kowalczyk R (2011) The effects of sex, age, season and habitat on diet of the red fox Vulpes vulpes in northeastern Poland. Acta Theriol 56: 209-218

Lacorcia L, Gasser RB, Anderson GA, Beveridge I (2009) Comparison of bronchoalveolar lavage fluid examination and other diagnostic techniques with the Baermann technique for detection of naturally occurring Aelurostrongylus abstrusus infection in cats. J Am Vet Med Assoc 235: 43-49

Maksimov P, Hermosilla C, Taubert A, Staubach C, Sauter-Louis C, Conraths FJ, Vrhovec MG, Pantchev N (2017) GIS-supported epidemiological analysis on canine Angiostrongylus vasorum and Crenosoma vulpis infections in Germany. Parasit Vectors 10: 108

McGarry JW, Morgan ER (2009) Identification of first-stage larvae of metastrongyles from dogs. Vet Rec 165: 258-261

Morelli S, Grillotti E, Russi I, Manzocchi S, Beraldo P, Viglietti A, Crisi PE, Pezzuto C, De Tommaso C, Pampurini F, Traversa D (2018) Large scale survey on the occurrence of canine and feline extraintestinal nematodes in Italy. XXX Congresso Nazionale SoIPa, p. 131

Segovia JM, Torres J, Miquel J (2004) Helminth parasites of the red fox (Vulpes vulpes L., 1758) in the Iberian Peninsula: an ecological study. Acta Parasitol 49: 67-79

Tolnai Z, Széll Z, Sréter T (2015) Environmental determinants of the spatial distribution of Angiostrongylus vasorum, Crenosoma vulpis and Eucoleus aerophilus in Hungary. Vet Parasitol 207: $355-358$ 
Toso S, Turra T, Gellini S, Matteucci C, Benassi MC, Zanni ML (1999) Vulpes vulpes. In Carta delle vocazioni faunistiche della regione Emilia-Romagna. Istituto Nazionale per la Fauna Selvatica S.T.E.R.N.A. pp 239-245

Traversa D, Di Cesare A, Conboy G (2010) Canine and feline cardiopulmonary parasitic nematodes in Europe: emerging and underestimated. Parasit Vectors 3: 62 
Tables

\begin{tabular}{|c|c|c|c|c|c|c|}
\hline & strata & $\begin{array}{l}n^{\circ} \text { for } \\
\text { strata }\end{array}$ & $\begin{array}{c}\mathbf{n}^{\circ} \text { of } \\
\text { positive }\end{array}$ & frequency & & \\
\hline \multirow[b]{2}{*}{ gender } & male & 32 & 9 & 0.28 & \multirow[b]{2}{*}{$\chi^{2}=0.26$} & \multirow{2}{*}{$\mathrm{p}=0.613$} \\
\hline & female & 31 & 7 & 0.23 & & \\
\hline \multirow{2}{*}{ province } & Forlì-Cesena & 51 & 11 & 0.22 & \multirow{2}{*}{$\chi^{2}=0.41$} & \multirow{2}{*}{$\mathrm{p}=0.523$} \\
\hline & Rimini & 35 & 13 & 0.37 & & \\
\hline \multirow{2}{*}{$\begin{array}{c}\text { geographical } \\
\text { features }\end{array}$} & flatland & 37 & 12 & 0.32 & \multirow{2}{*}{$\chi^{2}=1.85$} & \multirow{2}{*}{$\mathrm{p}=0.174$} \\
\hline & hill/mountain & 51 & 13 & 0.25 & & \\
\hline
\end{tabular}

Table 1. Foxes found positive for C. vulpis larvae, stratified on the basis of gender, province and geographical features. $\chi^{2}$ test does not show any statistical difference.

\begin{tabular}{|c|c|c|c|}
\hline \multirow{2}{*}{ European country } & \multicolumn{2}{|c|}{ C. vulpis } & \multirow{2}{*}{$\begin{array}{l}\text { Sample } \\
\text { size }\end{array}$} \\
\hline & & $95 \%(\mathrm{CI})$ & \\
\hline Netherlands (Borgsteede, 1984; Z Parasitenkd 70: 281-285) & 4.5 & - & 139 \\
\hline Portugal (Carvalho-Varela and Marcos, 1993; Acta Parasitol & 1.3 & - & 306 \\
\hline Croatia (Rajković-Janje et al., 2002; Z Jagdwiss 48: 151- & $>20$ & - & 85 \\
\hline Hungary (Sréter et al., 2003; Vet Parasitol 115: 329-334) & 24 & - & 100 \\
\hline Denmark (Saeed et al., 2006; Vet Parasitol 139: 168-179) & 17. & - & 748 \\
\hline Norway (Davidson et al., 2006; Vet Parasitol 136: 307-316) & 58 & - & 181 \\
\hline Lithuania (Bruẑinskaitè-Schmidhalter et al., 2012; Parasitol & 53. & $43.8-63.7$ & 310 \\
\hline Hungary (Tolnai et al., 2015; Vet Parasitol 207: 355-8) & 24. & $23.2-26$ & 937 \\
\hline Bosnia and Herzegovina (Hodžić et al., 2016; Vet Parasitol & 45. & $39.3-52.3$ & 221 \\
\hline \multicolumn{4}{|l|}{ Italy } \\
\hline Piomonte (Rossi et al., 1983; Parassitologia 25: 340-343) & 9.1 & - & 33 \\
\hline Tuscany (Poli et al., 1985; Erkrankungen der Zootiere, 507- & 3 & - & 35542 \\
\hline Trentino Alto Adige (Manfredi et al., 2003; J Mt Ecol 7: & 17.3 & - & 129 \\
\hline $\begin{array}{l}\text { 512) Tuscany (Magi et al., 2009; J Wildl Dis 45: } 881261- \\
\text { 263) -885) }\end{array}$ & 14.7 & - & \\
\hline Liguria and Piemonte (Magi et al., 2014; J Helminthol 89: & 15.88 .7 & $10.2-21.3$ & 165 \\
\hline Southern Italy (Latrofa et al., 2015; Parasitol Res 114: & 28.4 & - & 138 \\
\hline $\begin{array}{l}\text { 3611506-511) } \quad \text { Present } \\
\text { study3617) }\end{array}$ & & $19-37.8$ & 88 \\
\hline
\end{tabular}

Table 2. Prevalence of $C$. vulpis in different European countries and in different Italian regions.

Figure captions: 
Figure 1. Study area: Forli-Cesena, Rimini and Ravenna provinces, located on the easthern side of the Emilia-Romagna region. The yellow drawing pins indicate negative foxes; red drawing pins refer to positive foxes. 